\title{
Conhecimento e atitudes sobre câncer da mama e do colo do útero entre trabalhadoras da área de saúde
}

\author{
Gilberto Andrade Tavares \\ Marco Antônio Vasconcelos Rêgo
}

\section{SciELO Books / SciELO Livros / SciELO Libros}

TAVARES, G.A., and RÊGO, M.A.V. Conhecimento e atitudes sobre câncer da mama e do colo do útero entre trabalhadoras da área de saúde. In: FERNANDES, R.C.P., LIMA, M.A.G., and ARAÚJO, T.M., comps. Tópicos em saúde, ambiente e trabalho: um olhar ampliado [online]. Salvador: EDUFBA, 2014, pp. 385-421. ISBN: 978-65-5630-012-2. https://doi.org/10.7476/9786556300122.0020. \section{International license.}

All the contents of this work, except where otherwise noted, is licensed under a Creative Commons Attribution 4.0

Todo o conteúdo deste trabalho, exceto quando houver ressalva, é publicado sob a licença Creative Commons Atribição 4.0. 


\section{Conhecimento e atitudes sobre câncer da mama e do colo do útero entre trabalhadoras da área de saúde}

Gilberto Andrade Tavares

Marco Antônio Vasconcelos Rêgo

\section{Introdução}

O câncer da mama é um importante problema de saúde pública em todo o mundo. As repercussões dessa doença não se limitam ao corpo da mulher, e são também, de ordem econômica, psíquica e social. Trata-se da principal doença neoplásica do sexo feminino, tanto em países desenvolvidos quanto naqueles em desenvolvimento, com uma maior tendência de aumento das taxas de incidência nos países menos desenvolvidos. (AGARWAL et al., 2007) Por exemplo, mais de 200.000 novos casos de câncer invasivo da mama e 55.000 casos de câncer in situ são diagnosticados anualmente nos Estados Unidos da América (EUA). (BRODY; TICKNER; RUDEL, 2005) No Brasil, cerca de 53 mil casos eram esperados em 2012, o que significa quase $30 \%$ de todos os tumores do sexo feminino. Dentre esses casos, estima-se que 2.100 ocorram no estado da Bahia. (BRASIL, 2012)

A difusão da mamografia como principal forma de prevenção deste câncer nos EUA aumentou nos últimos 25 anos. Estima-se que $63 \%$ das mulheres entre 50 a 69 anos realizam mamografia entre nove a 20 meses, com média de 14 meses. (KERLIKOWSKE, 2009) Neste mesmo país, apesar do aumento na frequência da realização dos exames de detecção precoce do câncer da mama nas últimas décadas, as mulheres de baixa renda e as que compõem grupos étnicos minoritários têm sido menos rastreadas para câncer da mama que o restante da população. As principais barreiras para a realização da mamografia são: a falta de 
um médico de referência, custo, falta de percepção de risco e medo de exposição à radiação. (THOMPSON; MONTAÑO; MAHLOCH, 1997)

Outras questões apresentadas como barreiras aos métodos de prevenção são o pouco conhecimento sobre a doença, a cultura do indivíduo, o nível educacional e o medo do adoecimento e do morrer. Em um estudo entre mulheres hispânicas residentes nos EUA, em relação à percepção e conhecimento, descreveram-se a relação entre o câncer no geral e a morte, medo e/ou doença mortal. Quando perguntadas sobre as fontes de informação sobre o câncer, metade das entrevistadas respondeu que receberam nenhuma ou mínima informação sobre o câncer da mama. (LUQUIS; CRUZ, 2006)

A análise de recursos de multimídia interativos em um estudo recente, mostrou que aqueles recursos podem prover informações sobre saúde para mulheres de baixa educação e de minoria étnica. Os instrumentos utilizados expandiram o leque de ferramentas disponíveis para os educadores em saúde, tal como: materiais impressos, áudio, vídeo e outros recursos áudios-visuais. Esses recursos podem ser utilizados por educadores em saúde e ser uma ferramenta de manipulação de dados devido a sua capacidade eletrônica de armazenamento. Futuramente poderão ser usados em outros assuntos além do câncer da mama. (VALDEZ et al., 2002)

Portanto, para a adesão aos métodos de detecção, também são importantes a informação correta e o interesse do profissional de saúde. Em um estudo com enfermeiras em Cingapura, revelou-se que, apesar de uma agressiva política pública de educação nacional sobre o câncer da mama e os benefícios na detecção primária, 1,5\% das mulheres com câncer foram diagnosticadas com os estágios III e IV da doença. As enfermeiras, por serem importante grupo entre os profissionais da área de saúde, têm grande responsabilidade na educação pública nesta área. No entanto, foi detectado pouco conhecimento ou conhecimento equivocado. Este fato pode perpetuar preconceitos comuns e resultar em diagnóstico e tratamento tardios. (SEAN; TAN, 2007) Em um estudo entre médicos atuantes na rede pública e particular de saúde, demonstrou-se que o reconhecimento dos fatores de risco para o câncer da mama foi inadequado em relação às diretrizes do Ministério da Saúde. Essas recomendações de rastreamento do câncer da mama pareceram pouco claras aos médicos, com grande parte deles fornecendo respostas 
conflitantes. Os médicos identificaram escassez de equipamentos e o custo do exame como as principais barreiras à realização de mamografia, o que não coincidiu com a visão das mulheres atendidas. Os médicos pareciam receptivos às atividades de atualização. (GODINHO; $\mathrm{KOCH}, 2004$ )

O câncer do colo do útero é o segundo tipo mais comum de câncer entre as mulheres em todo o mundo. Na América Latina as taxas de incidência são quatro vezes maiores do que nos EUA e em outros países desenvolvidos. (DELUCA et al., 2004) As mais altas incidências são encontradas na África e no sudoeste da Ásia, em torno de 40 por 100.000 mulheres. (MURTA et al., 1999) No Brasil, cerca de 17 mil casos eram esperados em 2012, o que significa 9,3\% de todos os tumores do sexo feminino. Dentre esses, estima-se que 800 casos ocorram no estado da Bahia. (BRASIL, 2012)

Esta doença tem uma evolução lenta, apresentando fases pré-invasivas, caracterizadas por sua benignidade, conhecidas como neoplasias intraepiteliais cervicais (NIC). O rastreamento dessas lesões através do exame de Papanicolaou permite o diagnóstico precoce do tumor. (PINHO; MATTOS, 2002) Alguns estudos mostram uma cobertura satisfatória do exame preventivo em mulheres em idade fértil no Brasil. Em um estudo no Rio Grande do Sul, a cobertura de exame Papanicolaou foi de $65 \%$, superando a meta de $60 \%$ preconizada pelo Ministério da Saúde do Brasil no começo da década de 90, tendo como referência o Plano quinquenal de saúde 1990-1995. No entanto, preconiza-se que, a efetividade dos programas de controle para o câncer de colo uterino, deva atingir coberturas acima de 80\%. (COSTA et al., 1998) Em um estudo mais recente no Maranhão, a cobertura do Papanicolaou em mulheres de 25 a 49 anos, que já haviam iniciado a atividade sexual, foi de $82,4 \%$. Muitas mulheres realizaram o exame em intervalos curtos, o que pouco contribui para a prevenção da doença. (OLIVEIRA et al., 2006)

A cobertura pode ser ampliada se algumas barreiras à realização do exame forem superadas. Em um estudo com mulheres brasileiras com diagnóstico firmado para o câncer uterino, as principais barreiras para o diagnóstico e acompanhamento da doença, por elas apontadas, foram as seguintes: médicos que não as examinavam (60\% de todas as mulheres); tempo de espera longo para a consulta ( $48 \%$ daquelas com 
NIC e $60 \%$ daquelas com câncer invasivo) e agendamento tardio ( $47 \%$ das mulheres com NIC e 50\% das com câncer invasivo). (BRENNA et al., 2001)

A comunicação em saúde é um instrumento necessário para a sensibilização das mulheres na prevenção do câncer do colo do útero. Em uma revisão sobre o assunto, Britto da Cruz e Loureiro (2008), consideraram que a abordagem de comunicação com as mulheres na faixa etária proposta pelos programas de prevenção ainda se mostra deficiente. Isto pode ser explicado pelo fato que esta abordagem está sendo realizada sem identificação com estas mulheres, muitas vezes levando ao constrangimento por não terem suas histórias, vivências e valores contextualizados. Os autores ressaltam também que os fatores que desestimulam as mulheres, principalmente as que se encontram em grupos de maior vulnerabilidade social, a se envolverem nas campanhas preventivas para o câncer do colo do útero, podem estar muito além de suas dificuldades econômicas e de seu desconhecimento sobre a importância de realização dos exames. Portanto, os projetos que pretendem incluir essas mulheres nas campanhas devem considerar as questões culturais que as envolvem. Para isso, é importante que a linguagem utilizada seja menos tecnicista e mais adequada aos seus interesses e necessidades.

O conhecimento adequado entre os profissionais de saúde é essencial para uma boa prática de prevenção do câncer de colo do útero. No entanto, esta condição por muitas vezes não é alcançada. Num estudo com médicos mexicanos, incluindo ginecologistas atuantes em serviços de saúde público e privado, a maioria não tinha informação sobre as normas oficiais para o câncer do colo do útero. Foi também detectada discrepância na recomendação para periodicidade na realização do exame de Papanicolaou. No entanto, a grande maioria dos médicos (80\%) indicava que as suas pacientes realizassem o preventivo, o significado e benefícios em realizá-lo. Em relação ao manejo de lesões NIC I e NIC II, houve uma menor indicação de laserterapia ou crioterapia entre os clínicos gerais em comparação com os ginecologistas. (ALDRICH et al., 2005)

Além do conhecimento, é importante explorar o quanto este saber é transportado para a vida das profissionais da área da saúde, haja vista que a percepção do cuidado de sua saúde deverá transparecer no cuidado com a saúde do outro. Estudantes de enfermagem reconhe- 
ciam a necessidade de realizar a prevenção do câncer do colo do útero, assim como a sua periodicidade e a forma correta de fazerem tal prevenção. No entanto, algumas não o faziam com a periodicidade adequada. Os principais motivos para isso foram: não ter tido relação sexual vaginal e medo de ser portadora da doença. A prática discente deve ser reformulada, de forma a criar hábito de realização de exames preventivos, melhorando o estilo de vida e estudando sempre as inovações a respeito do tema. Todos esses aspectos têm o intuito de aprimorar o cuidar de si, para poder cuidar da saúde das mulheres com mais segurança, dignidade, sabedoria, humanização e o mais importante, com amor. (BEGHINI et al., 2006)

O objetivo desse estudo foi avaliar o nível de conhecimento sobre os cânceres de mama e do colo do útero entre trabalhadoras da área de saúde, e estabelecer uma associação entre o conhecimento e a prevenção primária da doença.

\section{Métodos}

Trata-se de um estudo de corte transversal, realizado de maio a setembro de 2011, em uma empresa de Serviço de Atenção Domiciliar (SAD), situada em Salvador e Lauro de Freitas, Bahia. Realizou-se um censo no qual foram entrevistadas 246 trabalhadoras da área de saúde, com idade entre 20 e 69 anos (médicas, enfermeiras, fisioterapeutas, fonoaudiólogas, nutricionistas, terapeutas ocupacionais, odontólogas, farmacêutica, técnicas em enfermagem, auxiliares de enfermagem, pessoal do serviço administrativo e do serviço geral).

As trabalhadoras responderam um questionário dividido em blocos. Inicialmente foram coletados dados sociodemográficos (idade, raça, estado civil, escolaridade, número de filhos, pessoas que residem no domicílio, renda mensal da família e meio de comunicação mais utilizado) e ocupacionais (vínculo empregatício, profissão/ocupação atual, tempo de serviço e experiência profissional com o câncer da mama).

No segundo bloco foi pesquisado o conhecimento sobre câncer da mama, onde foram abordados os principais fatores de risco (menarca precoce, nuliparidade, idade à primeira gestação a termo após os 30 anos, uso de anticoncepcionais orais, menopausa tardia, uso de terapia de reposição hormonal, idade, obesidade, dieta rica em gordura, 
herança genética, falta ou pouca atividade física programada, ingestão de moderada a elevada de álcool e exposição a radiações ionizantes entre os menores de 35 anos), sinais e sintomas dessa doença (nódulo, edema, retração da pele, pele em "casca de laranja”, eritema do seio; ulceração, sangramento e desvio da aréola e mamilo; nódulo em axilas), métodos de detecção precoce (mamografia e exame clínico da mama) e frequência para realização dos métodos de detecção (exame clínico da mama para todas as mulheres que procuram serviço de saúde, para as mulheres sem história de câncer da mama em parentes de primeiro grau anual a partir dos 40 anos até 49 anos; anualmente para aquelas com história positiva a partir dos 35 anos; mamografia para as mulheres sem história de câncer da mama em parentes de primeiro grau a cada dois anos a partir dos 50 anos até 69 anos; anualmente para aquelas com história positiva a partir dos 35 anos).

Ainda no segundo bloco foi pesquisado o conhecimento sobre câncer do colo do útero, onde foram questionados principais fatores de risco (infecção pelo HPV, tabagismo, baixa ingesta de vitaminas, multiplicidade de parceiros sexual, iniciação sexual precoce e uso de anticoncepcionais orais), sinais e sintomas dessa doença (hemorragia, corrimento vaginal e dor), método de prevenção primária (exame de Papanicolaou) e frequência para realização do método (para mulheres entre 25 a 59 anos de idade, inicialmente anual e, caso dois exames seguidos (em um intervalo de um ano) apresentassem resultado normal, o exame poderia passar a ser feito a cada três anos). Neste bloco, o questionário seguiu a lógica de pesquisa espontânea e induzida, ou seja, inicialmente a trabalhadora foi estimulada a responder sobre as questões conforme seus conhecimentos, sem apoio de alternativas. A resposta era correta quando a trabalhadora concordava com os parâmetros determinados no questionário. Os parâmetros foram definidos a partir de orientações do INCA e de outros estudos. (POWE et al., 2005; RODRÍGUEZ; WARD; PÉREZ-STABLE, 2005; FERREIRA; OLIVEIRA, 2006; LUIQUIS; CRUZ, 2006; SEAH; TAN, 2007; BRASIL, 2011a; BRASIL, 2011b)

Em seguida, a entrevistada foi questionada ativamente sobre os conhecimentos esperados. Novamente a resposta era correta quando a trabalhadora concordava com os parâmetros determinados no questionário. $\mathrm{Na}$ sequência, a entrevista focou o comportamento das 
entrevistadas no geral (religião, frequência de ida a igreja, culto ou terreiro; aceitação de conselhos sobre sua saúde por familiares, vizinho ou orientador espiritual), tipo de acesso aos serviços de saúde (convênio particular/empresa ou Sistema Único de Saúde) e comportamento sobre a detecção precoce (realização de consultas periódicas, compartilhamento de informações e resultados dos exames pelo médico ginecologista, segurança na orientação médica, acesso às informações sobre o câncer da mama e sobre o câncer do colo de útero, bem como sobre a finalidade da mamografia e do exame de Papanicolaou, respectivamente).

Foram perguntados os motivos para realização da mamografia: possuir histórico familiar positivo para câncer; influência de amigos; apoio e companhia do cônjuge; influência de familiares; solicitação médica; atendimento às campanhas sobre a doença; vontade própria; percepção dos sintomas da doença; consciência da importância da detecção precoce; estar na idade de realizar; por ser parte dos exames de rotina; facilidade para marcar o exame; afinidade com os técnicos que realizam o exame; facilidade de transporte ao local do exame e outros motivos. Foram também questionadas as barreiras que influenciaram a não realização do exame entre aquelas mulheres com indicação para fazê-lo: nunca ter pensado sobre o assunto; a mamografia é desnecessária por não ter problema nas mamas; não ter tempo; não recomendação médica do exame; alto custo do exame; descuido; não ter quem a acompanhe para realizar o exame; não ter histórico familiar para câncer; medo de sentir dor durante o exame; medo de descobrir doença; desconfiança no resultado do exame; não saber qual médico procurar para realizar o exame; não saber onde realizar o exame; achar que o exame expõe à radiação por raios $\mathrm{X}$; achar que a máquina ao pressionar a mama pode causar câncer; medo de ser mal tratada pelos técnicos que realizam o exame; informação negativa de parente, amigo ou colega sobre o exame e outras razões.

Da mesma forma, perguntou-se sobre os motivos para realização do exame de Papanicolaou: possuir histórico familiar positivo para câncer; influência de amigos; apoio e companhia do cônjuge; influência de familiares; solicitação médica; atendimento às campanhas sobre a doença; vontade própria; percepção dos sintomas da doença; consciência da importância na prevenção primária; estar na idade de realizar; por ser parte dos exames de rotina; se sentir vulnerável à doença e outros 
motivos. Foram também questionadas as barreiras que influenciaram a não realização do Papanicolaou entre aquelas mulheres com indicação para fazê-lo: nunca ter pensado sobre o assunto; considerar o exame de Papanicolaou desnecessário por não ter problemas ginecológicos; não ter tempo; não recomendação médica do exame; custo elevado do exame; descuido; não ter companhia para realizar o exame; não ter histórico familiar para câncer; medo de sentir dor durante o exame; medo de descobrir doença; desconfiança no resultado do exame; não saber qual médico procurar para realizar o exame; não saber onde realizar o exame; informação negativa de parente, amigo ou colega e outras razões.

Finalmente o questionário foi encerrado com um bloco sobre antecedentes médicos (idade da menarca em anos, início da atividade sexual, número de parceiros em toda vida e nos últimos 12 meses); história obstétrica (idade primeira gestação, número de gestações incluindo abortos e idade quando da menopausa); história pessoal para câncer (mama, colo do útero, endométrio, ovário, colón e/ou reto, traqueia, brônquios e pulmão; estômago, leucemia e outros); métodos anticoncepcionais (contraceptivo oral, injetável, uso de dispositivo intrauterino, preservativo, método da tabela, tempo de uso de método predominante); uso de terapia de reposição hormonal, número de infecções ginecológicas tratadas ou não tratadas no último ano; história familiar para os cânceres citados; anotações sobre estatura e peso atual para o cálculo do Índice de Massa Corpórea (IMC) informados pela entrevistada.

As variáveis independentes principais "nível de conhecimento sobre o câncer da mama" e "nível de conhecimento sobre o câncer do colo do útero" foram dicotomizadas em nível adequado (mais de 70\% de respostas corretas) e não adequado (menos de $70 \%$ das respostas corretas). Calcularam-se razões de prevalência (RP) considerando a realização de consultas de prevenção, da mamografia e do exame de Papanicolau como variáveis dependentes. Num segundo momento, as variáveis "conhecimento sobre câncer da mama" e "conhecimento sobre câncer do colo de útero" foram caracterizadas como dependentes, e calcularam-se as RP para verificação de fatores associados. Realizou-se análise de regressão logística com o procedimento backward através do programa estatístico SPPS 13. (SPSS, 2004) 
O estudo seguiu a orientação da declaração de Helsinque de 1989 e da Rsolução no 196/96, sobre pesquisa envolvendo seres humanos do Conselho Nacional de Saúde, sendo aprovada no Comitê de Ética em Pesquisa da Escola Estadual de Saúde Pública (EESP), parecer 04/2011. As entrevistadas e o coordenador do estudo assinaram o Termo de Consentimento Livre e Esclarecido.

\section{Resultados}

Das 385 trabalhadoras da empresa de SAD, 246 (63,9\%) participaram do estudo. A maioria das trabalhadoras tinha de 20 a 29 anos $(41,5 \%)$, variando entre 20 e 58 anos, com média de 36,1 anos e mediana de 35 anos. Aproximadamente metade das trabalhadoras $(49,6 \%)$ se declarou parda. Quanto à escolaridade, 146 (59,3\%) possuíam ensino médio completo e $48(19,5 \%)$ possuíam pós-graduação. Cento e treze $(45,9 \%)$ não tinham filhos e $127(51,6 \%)$ possuíam até três filhos. A maioria $(64,6 \%)$ recebia entre um a cinco salários mínimos. Em relação ao vínculo de trabalho junto à empresa, 146 (59,3\%) eram cooperadas e $82(33,3 \%)$ eram empregadas com carteira assinada. Cerca de $60 \%$ eram auxiliares de enfermagem. Cento e setenta e oito trabalhadoras $(72,4 \%)$ possuíam entre um e nove anos de serviço.

Para o grupo de trabalhadoras da área de saúde, com indicação para realizar mamografia regularmente, os principais motivos que as levavam a realizar o exame foram: consciência da prevenção (96,9\%), estar na idade de realizar $(89,2 \%)$, por ser exame de rotina $(87,7 \%)$, solicitação médica $(84,6 \%)$ e por vontade própria $(75,3 \%)$ (Tabela 1 ). As principais barreiras que as impediam de realizar o exame foram: descuido e falta de tempo $(66,6 \%)$, alto custo do exame $(44,4 \%)$ e medo de ser mal tratada durante o exame $(33,3 \%)$. 
Tabela 1 - Características das trabalhadoras da área de saúde ${ }^{(1)}$ em relação aos motivos para realização da mamografia ${ }^{(2)}$ em Empresa de Atenção Domiciliar Salvador e Região, 2011.

\begin{tabular}{l|l|l}
\hline \multicolumn{1}{c|}{ Variável } & $\mathrm{n}=65$ & \multicolumn{1}{c}{$\%$} \\
\hline Consciência da prevenção & 63 & 96,9 \\
\hline Estar na idade de realizar o exame & 58 & 89,2 \\
\hline Exame de rotina & 57 & 87,7 \\
\hline Solicitação médica & 55 & 84,6 \\
\hline Vontade própria & 49 & 75,3 \\
\hline Facilidade de transporte & 45 & 69,2 \\
\hline Facilidade de marcação & 37 & 56,9 \\
\hline Afinidade com os técnicos que realizam o exame & 31 & 47,7 \\
\hline Influência de campanhas & 25 & 38,5 \\
\hline Se sentir Vulnerável a doença & 23 & 35,4 \\
\hline Outras razões & 23 & 35,3 \\
\hline Histórico familiar positivo para câncer & 22 & 33,8 \\
\hline Influência do cônjuge & 15 & 23,1 \\
\hline Percepção de sinais da doença & 14 & 21,5 \\
\hline Influência de familiares & 09 & 13,8 \\
\hline
\end{tabular}

(1) Excluídas as não envolvidas diretamente na assistência ao paciente.

(2) Excluídas as que não realizaram mamografia nos últimos 02 anos, nunca ter realizado ou não estar na idade de realizar.

Fonte: (TAVARES; RÊGO, 2011)

O nível de conhecimento sobre o câncer da mama esteve mais associado ao compartilhamento de resultados de exames de detecção precoce da doença $(\mathrm{RP}=1,53)$ e informações em geral $(\mathrm{RP}=1,39)$ por parte do médico. Histórico familiar positivo para câncer da mama $(\mathrm{RP}=$ $1,18)$ também pode estar envolvido (Tabela 2 ). A realização de consultas para detecção precoce do câncer da mama foi associada: ao médico ginecologista ter o hábito de examinar as mamas $(\mathrm{RP}=1,26)$, de compartilhar informações $(\mathrm{RP}=1,31)$ e compartilhar os resultados dos exames de detecção precoce da doença $(\mathrm{RP}=1,24)$. As demais variáveis não foram relevantes (Tabela 3). Na análise multivariada, mantiveram-se as associações entre a realização de consultas de detecção precoce do câncer da mama com o exame das mamas pelo médico ginecologista, com Odds Ratio (OR) igual a 4,45 e o compartilhamento de informações pelo mesmo profissional $(\mathrm{OR}=3,40)$. 
Tabela 2 - Razões de Prevalência (RP) entre conhecimento sobre câncer da mama e variáveis sociodemográficas, ocupacionais, atitudes para detecção precoce do câncer da mama e histórico familiar para câncer entre trabalhadoras da área de saúde de empresa de Atenção Domiciliar Salvador e Região, 2011, (n=246).

\begin{tabular}{|c|c|c|c|c|c|}
\hline Variável & \multicolumn{5}{|c|}{ Conhecimento } \\
\hline & \multicolumn{2}{|c|}{ Adequado } & \multicolumn{2}{|c|}{ Não adequado } & \multirow[b]{2}{*}{ RP } \\
\hline Idade & $\mathbf{N}$ & $\%$ & $\mathrm{n}$ & $\%$ & \\
\hline$>40$ anos & 53 & 63,1 & 31 & 36,9 & 0,96 \\
\hline$<40$ anos & 106 & 65,4 & 56 & 34,6 & \\
\hline \multicolumn{6}{|l|}{ Escolaridade } \\
\hline$>$ Superior incompleto & 66 & 69,5 & 29 & 30,5 & 1,13 \\
\hline$<$ Ensino médio & 93 & 61,6 & 58 & 38,4 & \\
\hline \multicolumn{6}{|l|}{ Renda } \\
\hline >05 Salários Mínimos & 58 & 66,7 & 29 & 33,3 & 1,05 \\
\hline < 05 Salários Mínimos & 101 & 63,5 & 58 & 36,5 & \\
\hline \multicolumn{6}{|l|}{ Acesso aos serviços de saúde } \\
\hline Convênio particular/empresa & 92 & 67,2 & 45 & 32,8 & 0,73 \\
\hline Atendimento Sistema Único de Saúde & 67 & 61,5 & 42 & 38,5 & \\
\hline \multicolumn{6}{|l|}{ Profissional da área de saúde } \\
\hline Sim & 123 & 60,6 & 80 & 39,4 & 0,73 \\
\hline Não & 36 & 83,7 & 07 & 16,3 & \\
\hline \multicolumn{6}{|c|}{ Experiência profissional com câncer da mama ${ }^{(1)}$} \\
\hline Sim & 50 & 64,1 & 28 & 35,9 & 1,10 \\
\hline Não & 73 & 58,4 & 52 & 41,6 & \\
\hline \multicolumn{6}{|l|}{ Tempo de serviço } \\
\hline$>10$ anos & 42 & 61,8 & 26 & 38,2 & 0,94 \\
\hline$<10$ anos & 117 & 65,7 & 61 & 34,3 & \\
\hline \multicolumn{6}{|c|}{ Acesso informação sobre câncer da mama } \\
\hline Sim & 130 & 66,0 & 67 & 34,0 & 1,11 \\
\hline Não & 29 & 59,2 & 20 & 40,8 & \\
\hline \multicolumn{6}{|c|}{ Médico compartilha informações sobre câncer da mama } \\
\hline Sim & 149 & 66,2 & 76 & 33,8 & 1,39 \\
\hline Não & 10 & 47,6 & 11 & 52,4 & \\
\hline \multicolumn{6}{|c|}{ Médico compartilha resultados dos exames de detecção precoce do câncer da mama } \\
\hline Sim & 152 & 66,1 & 78 & 33,9 & 1,53 \\
\hline Não & 07 & 43,8 & 09 & 56,3 & \\
\hline
\end{tabular}




\begin{tabular}{l|l|l|l|l|l}
\hline Médico tem hábito de examinar as mamas \\
\hline Sim & 131 & 66,5 & 66 & 33,5 & 1,16 \\
\hline Não & 28 & 57,1 & 21 & 42,9 & \\
\hline Histórico familiar positiva para câncer & 07 & 41,2 & 10 & 58,8 & 0,62 \\
\hline Sim & 152 & 66,4 & 77 & 33,6 & \\
\hline Não & \multicolumn{7}{|l}{} & & \\
\hline Histórico familiar positiva para câncer da mama & $(2)$ & 44,4 & 05 & 55,6 & 1,18 \\
\hline Sim & 04 & 47,5 & 05 & 62,5 & \\
\hline Não & 03 & 37 &
\end{tabular}

Excluídas as não envolvidas diretamente na assistência ao paciente Excluídas as sem antecedentes para câncer.

Fonte: (TAVARES; RÊGO, 2011)

Tabela 3 - Associação entre realização de consultas para detecção precoce do câncer da mama e variáveis sociodemográficas, ocupacionais, atitudes para detecção do câncer da mama e histórico familiar para câncer entre trabalhadoras da área de saúde

(1) de empresa de Atenção Domiciliar Salvador e Região, 2011, (n=203).

\begin{tabular}{|c|c|c|c|c|c|}
\hline Variável & \multicolumn{4}{|c|}{ Realização consultas } & \\
\hline & \multicolumn{2}{|l|}{ Sim } & \multicolumn{2}{|c|}{ Não } & \\
\hline Idade & $\mathrm{n}$ & $\%$ & $\mathbf{N}$ & $\%$ & RP \\
\hline$>40$ anos & 63 & 90,0 & 07 & 10,0 & 0,99 \\
\hline$<40$ anos & 120 & 90,2 & 13 & 9,8 & \\
\hline \multicolumn{6}{|l|}{ Escolaridade } \\
\hline$>$ Superior incompleto & 63 & 91,3 & 06 & 8,7 & 1,02 \\
\hline$<$ Ensino médio & 120 & 89,6 & 14 & 10,4 & \\
\hline \multicolumn{6}{|l|}{ Renda } \\
\hline > 05 Salários Mínimos & 64 & 90,1 & 07 & 9,9 & 1,00 \\
\hline < 05 Salários Mínimos & 119 & 90,2 & 13 & 9,8 & \\
\hline \multicolumn{6}{|l|}{ Acesso aos serviços de saúde } \\
\hline Convênio particular & 91 & 91,0 & 09 & 9,0 & 1,02 \\
\hline Sistema Único de Saúde & 92 & 89,3 & 11 & 10,7 & \\
\hline \multicolumn{6}{|l|}{ Tempo de serviço } \\
\hline$>10$ anos & 57 & 93,4 & 04 & 6,6 & 1,05 \\
\hline$<10$ anos & 126 & 88,7 & 16 & 11,3 & \\
\hline \multicolumn{6}{|c|}{ Experiência profissional com câncer da mama } \\
\hline Sim & 74 & 94,9 & 04 & 5,1 & 1,08 \\
\hline
\end{tabular}




\begin{tabular}{|c|c|c|c|c|c|}
\hline Não & 109 & 87,2 & 16 & 12,8 & \\
\hline \multicolumn{6}{|c|}{ Acesso informação sobre câncer da mama } \\
\hline Sim & 150 & 90,9 & 15 & 9,1 & 1,06 \\
\hline Não & 33 & 86,8 & 05 & 13,2 & \\
\hline \multicolumn{6}{|c|}{ Conhecimento sobre câncer da mama } \\
\hline Adequado & 113 & 91,9 & 10 & 8,1 & 1,04 \\
\hline Não adequado & 70 & 87,5 & 10 & 12,5 & \\
\hline \multicolumn{6}{|c|}{ Médico compartilha informações sobre câncer da mama } \\
\hline Sim & 169 & 92,3 & 14 & 7,7 & 1,31 \\
\hline Não & 14 & 70,0 & 06 & 30,0 & \\
\hline \multicolumn{6}{|c|}{ Médico compartilha resultados dos exames de detecção precoce do câncer da mama } \\
\hline Sim & 172 & 91,5 & 16 & 8,5 & 1,24 \\
\hline Não & 11 & 73,3 & 04 & 26,7 & \\
\hline \multicolumn{6}{|c|}{ Médico tem hábito de examinar as mamas } \\
\hline Sim & 150 & 94,3 & 09 & 5,7 & 1,26 \\
\hline Não & 33 & 75,0 & 11 & 25,0 & \\
\hline \multicolumn{6}{|c|}{ Histórico familiar positiva para câncer } \\
\hline Sim & 14 & 100,0 & 0 & 0,0 & 1,12 \\
\hline Não & 169 & 89,4 & 20 & 10,6 & \\
\hline
\end{tabular}

Excluídas as não envolvidas diretamente na assistência ao paciente.

Fonte: (TAVARES; RÊGO, 2011)

Avaliando a realização de mamografia para detecção precoce do câncer da mama, as principais associações foram: conhecimento adequado sobre câncer da mama $(\mathrm{RP}=1,26)$ e acessos aos serviços de saúde por convênio particular ou da empresa $(\mathrm{RP}=1,20)$ (Tabela 4). Na análise multivariada observaram-se associações entre a realização de mamografia e conhecimento adequado sobre o câncer da mama $(\mathrm{OR}=6,13)$, acesso aos serviços de saúde através de convênio particular ou empresa $(\mathrm{OR}=5,40)$ e tempo de serviço maior que 10 anos $(\mathrm{OR}=3,62)$. 
Tabela 4 - Associação entre realização de mamografia para detecção precoce do câncer da mama e variáveis sociodemográficas, ocupacionais, atitudes para detecção do câncer da mama e histórico familiar para câncer no geral e câncer da mama em trabalhadoras da área de saúde ${ }^{(1)}$ de empresa de Atenção Domiciliar Salvador e Região, 2011, $(n=74)$.

\begin{tabular}{|c|c|c|c|c|c|}
\hline Variável & \multicolumn{4}{|c|}{ Realização mamografia } & \\
\hline & \multicolumn{2}{|c|}{ Sim } & \multicolumn{2}{|c|}{ Não } & \\
\hline Idade $^{(2)}$ & $\mathrm{N}$ & $\%$ & $\mathrm{n}$ & $\%$ & $\mathrm{RP}$ \\
\hline$>45$ anos & 30 & 83,3 & 06 & 16,7 & 0,90 \\
\hline$<45$ anos & 35 & 92,1 & 03 & 0,9 & \\
\hline
\end{tabular}

\begin{tabular}{|c|c|c|c|c|c|}
\hline & & & & & \\
\hline$>$ Superior incompleto & 20 & 95,2 & 01 & 4,8 & 1,13 \\
\hline$<$ Ensino médio & 45 & 84,9 & 08 & 15,1 & \\
\hline
\end{tabular}

\begin{tabular}{l|l|l|l|l|l}
\hline Renda & 22 & 88,0 & 03 & 12,0 & 1,01 \\
\hline$>05$ Salários Mínimos & 43 & 87,7 & 06 & 12,3 & \\
\hline$<05$ Salários Mínimos & 43 & \\
\hline
\end{tabular}

\begin{tabular}{l|l|l|l|l|l}
\hline Acesso aos serviços de saúde & 38 & 95,0 & 02 & 5,0 & 1,20 \\
\hline Convênio particular & 27 & 79,4 & 07 & 20,6 & \\
\hline Sistema Único de Saúde &
\end{tabular}

Tempo de serviço

\begin{tabular}{l|l|l|l|l|l}
\hline$>10$ anos & 35 & 94,6 & 02 & 5,4 & 1,16 \\
\hline$<10$ anos & 30 & 81,1 & 07 & 18,9 & \\
\hline
\end{tabular}

Experiência profissional com câncer da mama

\begin{tabular}{l|l|l|l|l|l}
\hline Sim & 36 & 92,3 & 03 & 7,7 & 1,12 \\
\hline Não & 29 & 82,9 & 06 & 17,1 & \\
\hline
\end{tabular}

Acesso informação sobre câncer da mama

\begin{tabular}{l|l|l|l|l|l}
\hline Sim & 58 & 89,2 & 07 & 10,8 & 1,14 \\
\hline Não & 07 & 77,7 & 02 & 22,3 & \\
\hline
\end{tabular}

Conhecimento sobre câncer da mama

\begin{tabular}{l|l|l|l|l|l}
\hline Adequado & 42 & 95,4 & 02 & 4,6 & 1,26 \\
\hline Não adequado & 23 & 76,7 & 07 & 23,3 & \\
\hline
\end{tabular}

Médico compartilha informações sobre câncer da mama

\begin{tabular}{l|l|l|l|l|l}
\hline Sim & 63 & 87,5 & 09 & 12,5 & 0,87 \\
\hline Não & 02 & 100,0 & 0 & 0,0 & \\
\hline
\end{tabular}

Médico compartilha resultados dos exames de detecção precoce

\begin{tabular}{l|l|l|l|l|l}
\hline Sim & 63 & 88,7 & 08 & 11,3 & 1,76 \\
\hline Não & 02 & 66,6 & 01 & 33,4 & \\
\hline
\end{tabular}

Médico tem hábito de examinar as mamas 


\begin{tabular}{l|l|l|l|l|l}
\hline Sim & 58 & 89,2 & 07 & 10,8 & 1,14 \\
\hline Não & 07 & 77,7 & 02 & 22,3 & \\
\hline Histórico familiar positiva para câncer & 05 & 100,0 & 0 & 0,0 & 1,16 \\
\hline Sim & 60 & 86,9 & 09 & 13,1 & \\
\hline Não & 05 &
\end{tabular}

Excluídas as não envolvidas diretamente na assistência ao paciente, que nunca realizaram mamografia ou não estar na idade de realizar.

Ajustada para o grupo de trabalhadoras com indicação para realização da mamografia.

Fonte: (TAVARES; RÊGO, 2011)

Para o grupo de trabalhadoras da área de saúde com indicação para realizar o exame de Papanicolaou, os principais motivos que as levavam a realizar o exame foram: ser um exame de rotina $(98,4 \%)$, consciência da prevenção primária do câncer $(97,9 \%)$, vontade própria $(96,8 \%)$, estar na idade de realizar $(93,7 \%)$ e por solicitação médica $(71,0 \%)$ (Tabela 5). As principais barreiras que as impediam de realizar o exame foram: descuido e falta de tempo $(72,7 \%)$, considerar o exame desnecessário por não ter problemas ginecológicos, alto custo do exame e medo de descobrir doença $(27,3 \%)$. 
Tabela 5 - Características das trabalhadoras da área de saúde ${ }^{(1)}$ em relação aos motivos para realização do exame de Papanicolaou ${ }^{(2)} \mathrm{em}$ Empresa de Atenção Domiciliar Salvador e Região, 2011.

\begin{tabular}{l|c|c}
\multicolumn{1}{c|}{ Variável } & $\mathbf{n = 1 9 0}$ & $\%$ \\
\hline Exame de rotina & 187 & 98,4 \\
\hline Consciência da prevenção & 186 & 97,9 \\
\hline Vontade própria & 184 & 96,8 \\
\hline Estar na idade realizar o exame & 178 & 93,7 \\
\hline Solicitação médica & 135 & 71,0 \\
\hline Influência de campanhas & 88 & 46,3 \\
\hline Sentir-se vulnerável à doença & 80 & 42,1 \\
\hline Influência do cônjuge & 42 & 22,1 \\
\hline Histórico familiar positivo para câncer & 30 & 15,8 \\
\hline Percepção de sinais/sintomas da doença & 28 & 14,7 \\
\hline Influência de familiares & 20 & 10,5 \\
\hline Outras razões & 14 & 7,3 \\
\hline
\end{tabular}

Excluídas as não envolvidas diretamente na assistência ao paciente.

Excluídas as que não realizaram o exame de Papanicola ou nos últimos três anos, nunca ter realizado ou não estar na idade de realizar.

Fonte: (TAVARES; RÊGO, 2011)

O nível de conhecimento sobre o câncer do colo do útero esteve mais associado à história familiar positiva para câncer $(\mathrm{RP}=1,20)$ e ser profissional da área da saúde $(\mathrm{RP}=1,17)$. Renda mensal da família maior que cinco salários mínimos $(\mathrm{RP}=1,10)$ também pode estar envolvida (Tabela 6). A realização de consultas de prevenção primária para o câncer do colo do útero foi associada: ao médico ginecologista compartilhar as informações $(\mathrm{RP}=1,32)$ e os resultados dos exames $(\mathrm{RP}=1,25)$. As demais variáveis não foram relevantes (Tabela 7). Na análise multivariada, manteve-se a associação entre a realização de consultas de prevenção e compartilhamento de informações sobre o câncer do colo do útero pelo médico ginecologista $(\mathrm{OR}=6,87)$. 
Tabela 6 - Razões de Prevalência (RP) entre conhecimento sobre câncer do colo do útero e variáveis sociodemográficas, ocupacionais, atitudes para prevenção primária do câncer do colo do útero e histórico familiar para câncer entre trabalhadoras da área de saúde de empresa de Atenção Domiciliar Salvador e Região, 2011, (n=246).

\begin{tabular}{|c|c|c|c|c|c|}
\hline \multirow[t]{3}{*}{ Variável } & \multicolumn{4}{|c|}{ Conhecimento } & \multirow[b]{3}{*}{$\mathrm{RP}$} \\
\hline & \multicolumn{2}{|c|}{ Adequado } & \multicolumn{2}{|c|}{ Não adequado } & \\
\hline & $\mathrm{n}$ & $\%$ & $\mathrm{n}$ & $\%$ & \\
\hline$>36$ anos & 77 & 67,5 & 37 & 32,5 & 0,96 \\
\hline$<36$ anos & 93 & 70,5 & 39 & 29,5 & \\
\hline \multicolumn{6}{|l|}{ Escolaridade } \\
\hline$>$ Superior incompleto & 68 & 71,6 & 27 & 28,4 & 1,06 \\
\hline$<$ Ensino médio & 102 & 67,5 & 49 & 32,5 & \\
\hline \multicolumn{6}{|c|}{ Renda mensal média familiar } \\
\hline > 05 Salários Mínimos & 64 & 73,6 & 23 & 26,4 & 1,10 \\
\hline < 05 Salários Mínimos & 106 & 66,7 & 53 & 33,3 & \\
\hline \multicolumn{6}{|c|}{ Acesso aos serviços de saúde } \\
\hline Convênio particular & 95 & 69,3 & 42 & 30,7 & 1,01 \\
\hline Sistema Único de Saúde & 75 & 68,8 & 34 & 31,2 & \\
\hline \multicolumn{6}{|c|}{ Profissional da área da saúde } \\
\hline Sim & 144 & 70,9 & 59 & 29,1 & 1,17 \\
\hline Não & 26 & 60,5 & 17 & 39,5 & \\
\hline \multicolumn{6}{|l|}{ Tempo de serviço } \\
\hline$>10$ anos & 44 & 64,7 & 24 & 35,3 & 0,91 \\
\hline$<10$ anos & 126 & 70,8 & 52 & 29,2 & \\
\hline \multicolumn{6}{|c|}{ Experiência profissional com câncer do colo do útero ${ }^{(1)}$} \\
\hline Sim & 35 & 74,5 & 12 & 25,5 & 1,06 \\
\hline Não & 109 & 69,9 & 47 & 30,1 & \\
\hline \multicolumn{6}{|c|}{ Acesso a informação sobre câncer do colo do útero } \\
\hline Sim & 134 & 69,1 & 60 & 30,9 & 0,99 \\
\hline Não & 36 & 69,2 & 16 & 30,8 & \\
\hline \multicolumn{6}{|c|}{ Médico compartilha informações sobre câncer do colo do útero } \\
\hline Sim & 153 & 68,0 & 72 & 32,0 & 0,84 \\
\hline Não & 17 & 81,0 & 04 & 19,0 & \\
\hline \multicolumn{6}{|c|}{ Médico compartilha resultados dos exames de prevenção primária } \\
\hline Sim & 159 & 69,1 & 71 & 30,9 & 1,00 \\
\hline Não & 11 & 68,8 & 05 & 31,3 & \\
\hline
\end{tabular}




\begin{tabular}{|c|c|c|c|c|c|}
\hline \multicolumn{6}{|c|}{ Histórico familiar positivo para câncer } \\
\hline Sim & 14 & 82,4 & 03 & 17,6 & 1,20 \\
\hline Não & 156 & 68,1 & 73 & 31,9 & \\
\hline \multicolumn{6}{|c|}{ Histórico familiar positivo para câncer do colo do útero ${ }^{(2)}$} \\
\hline Sim & 06 & 75,0 & 02 & 25,0 & 0,85 \\
\hline Não & 08 & 88,9 & 01 & 11,1 & \\
\hline
\end{tabular}

Excluídas as não envolvidas diretamente na assistência ao paciente.

Excluídas as sem histórico familiar para câncer.

FONTE: (TAVARES; RÊGO, 2011)

Tabela 7 - Associação entre realização de consultas para prevenção primária do câncer do colo do útero e variáveis sociodemográficas, ocupacionais, atitudes para prevenção primária do colo do útero e histórico familiar para câncer entre trabalhadoras da área de saúde ${ }^{(1)}$ de empresa de Atenção Domiciliar Salvador e Região, 2011, (n=203).

\begin{tabular}{|c|c|c|c|c|c|}
\hline Variável & \multicolumn{4}{|c|}{ Realização de consultas } & \multirow[b]{2}{*}{$\mathrm{RP}$} \\
\hline & \multicolumn{2}{|c|}{ Sim } & \multicolumn{2}{|c|}{ Não } & \\
\hline I dade & $\mathrm{n}$ & $\%$ & $\mathbf{N}$ & $\%$ & \\
\hline$>36$ anos & 83 & 87,4 & 12 & 12,6 & 0,94 \\
\hline$<36$ anos & 100 & 92,6 & 08 & 7,4 & \\
\hline \multicolumn{6}{|l|}{ Escolaridade } \\
\hline$>$ Superior incompleto & 63 & 91,3 & 06 & 8,7 & 1,02 \\
\hline$<$ Ensino médio & 120 & 89,6 & 14 & 10,4 & \\
\hline \multicolumn{6}{|l|}{ Renda mensal média familiar } \\
\hline > 05 Salários Mínimos & 64 & 90,1 & 07 & 9,9 & 1,00 \\
\hline < 05 Salários Mínimos & 119 & 90,2 & 13 & 9,8 & \\
\hline \multicolumn{6}{|l|}{ Acesso serviços de saúde } \\
\hline Convênio particular & 91 & 91,0 & 09 & 9,0 & 1,02 \\
\hline Sistema Único de Saúde & 92 & 89,3 & 11 & 10,7 & \\
\hline \multicolumn{6}{|l|}{ Tempo de serviço } \\
\hline$>10$ anos & 57 & 93,4 & 04 & 6,6 & 1,05 \\
\hline$<10$ anos & 126 & 88,7 & 16 & 11,3 & \\
\hline \multicolumn{6}{|c|}{ Experiência profissional câncer do colo do útero } \\
\hline Sim & 43 & 91,5 & 04 & 8,5 & 1,02 \\
\hline Não & 140 & 89,7 & 16 & 10,3 & \\
\hline \multicolumn{6}{|c|}{ Acesso informação câncer do colo do útero } \\
\hline $\operatorname{Sim}$ & 145 & 90,6 & 15 & 9,4 & 1,03 \\
\hline Não & 38 & 88,4 & 05 & 11,6 & \\
\hline
\end{tabular}


Conhecimento adequado sobre câncer do colo do útero

\begin{tabular}{l|l|l|l|l|l}
\hline Sim & 131 & 91,0 & 13 & 9,0 & 1,03 \\
\hline Não & 52 & 88,1 & 07 & 11,9 & \\
\hline
\end{tabular}

Médico compartilha informações sobre câncer do colo do útero

\begin{tabular}{l|l|l|l|l|l} 
Sim & 169 & 92,3 & 14 & 7,7 & 1,32 \\
\hline Não & 14 & 70,0 & 06 & 30,6 & \\
\hline
\end{tabular}

Médico compartilha resultados dos exames de prevenção primária

\begin{tabular}{l|l|l|l|l|l}
\hline Sim & 172 & 91,5 & 16 & 8,5 & 1,25 \\
\hline Não & 11 & 73,3 & 04 & 26,7 &
\end{tabular}

Histórico familiar positivo para câncer

\begin{tabular}{l|l|l|l|l|l}
\hline Sim & 12 & 92,3 & 01 & 7,7 & 1,02 \\
\hline Não & 171 & 90,0 & 19 & 10,0 & \\
\hline
\end{tabular}

Histórico familiar positivo para câncer do colo do útero ${ }^{(2)}$

\begin{tabular}{l|l|l|l|l|l} 
Sim & 05 & 83,3 & 01 & 16,7 & 0,83 \\
\hline Não & 07 & 100,0 & 0 & 0,0 & \\
\hline
\end{tabular}

Excluídas as não envolvidas diretamente na assistência ao paciente.

Excluídas as sem histórico familiar para câncer.

Fonte: (TAVARES; RÊGO, 2011)

Avaliando a realização do exame de Papanicolaou para prevenção primária do câncer do colo do útero, a associação mais importante foi com o fato de o médico compartilhar informações sobre o câncer do colo do útero $(\mathrm{RP}=1,20)$ (Tabela 8$)$. $\mathrm{Na}$ análise multivariada observaram-se associações da realização do exame de Papanicolaou entre as trabalhadoras da área da saúde com compartilhamento de informações pelo médico $(\mathrm{OR}=7,85)$ e escolaridade maior ou igual ao nível superior incompleto $(\mathrm{OR}=5,33)$.

Tabela 8 - Associação entre realização do exame de Papanicolaou para prevenção primária do câncer do colo do útero e variáveis sociodemográficas, ocupacionais, atitudes para prevenção primária do câncer do colo do útero e histórico familiar para câncer em trabalhadoras da área de saúde ${ }^{(1)}$ de empresa de Atenção Domiciliar Salvador e Região, 2011, (n=201).

\begin{tabular}{|l|l|l|l|l|l|l}
\hline & \multicolumn{5}{c|}{ Realização do Papanicolaou } & \\
\hline \multicolumn{1}{c|}{ Variável } & \multicolumn{2}{c|}{ Sim } & \multicolumn{2}{c|}{ Não } & RP \\
\hline Idade & $\mathbf{n}$ & $\%$ & $\mathbf{n}$ & $\%$ & \\
\hline$>36$ anos & 89 & 94,7 & 05 & 5,3 & 0,99 \\
\hline$<36$ anos & 102 & 95,3 & 05 & 4,7 & \\
\hline
\end{tabular}




\begin{tabular}{|c|c|c|c|c|c|}
\hline \multicolumn{6}{|l|}{ Escolaridade } \\
\hline$>$ Superior incompleto & 67 & 98,5 & 01 & 1,5 & 1,06 \\
\hline$<$ Ensino médio & 124 & 93,2 & 09 & 6,8 & \\
\hline \multicolumn{6}{|c|}{ Renda mensal média familiar } \\
\hline > 05 Salários Mínimos & 67 & 97,1 & 02 & 2,9 & 1,03 \\
\hline < 05 Salários Mínimos & 124 & 93,6 & 08 & 6,1 & \\
\hline \multicolumn{6}{|c|}{ Acesso aos serviços de saúde } \\
\hline Convênio particular & 95 & 96,9 & 03 & 3,1 & 1,04 \\
\hline Sistema Único de Saúde & 96 & 93,2 & 07 & 6,8 & \\
\hline \multicolumn{6}{|l|}{ Tempo de serviço } \\
\hline$>10$ anos & 58 & 98,3 & 01 & 1,7 & 1,05 \\
\hline$<10$ anos & 133 & 93,7 & 09 & 6,3 & \\
\hline \multicolumn{6}{|c|}{ Experiência profissional com câncer do colo do útero } \\
\hline Sim & 43 & 93,5 & 03 & 6,5 & 0,98 \\
\hline Não & 148 & 95,5 & 07 & 4,5 & \\
\hline \multicolumn{6}{|c|}{ Acesso informação sobre câncer do colo do útero } \\
\hline Sim & 151 & 95,0 & 08 & 5,0 & 0,99 \\
\hline Não & 40 & 95,2 & 02 & 4,8 & \\
\hline \multicolumn{6}{|c|}{ Conhecimento adequado sobre câncer do colo do útero } \\
\hline Sim & 134 & 94,4 & 08 & 5,6 & 0,97 \\
\hline Não & 57 & 96,6 & 02 & 3,4 & \\
\hline \multicolumn{6}{|c|}{ Médico compartilha informações sobre câncer do colo do útero } \\
\hline Sim & 175 & 96,7 & 06 & 3,3 & 1,20 \\
\hline Não & 16 & 80,0 & 04 & 20,0 & \\
\hline \multicolumn{6}{|c|}{ Médico compartilha resultados dos exames de prevenção primária } \\
\hline Sim & 177 & 95,2 & 09 & 4,8 & 1,02 \\
\hline Não & 14 & 93,3 & 01 & 6,7 & \\
\hline \multicolumn{6}{|c|}{ Vergonha de realizar Papanicolaou } \\
\hline Não & 143 & 94,7 & 08 & 5,3 & 0,98 \\
\hline Sim & 48 & 96,0 & 02 & 4,0 & \\
\hline \multicolumn{6}{|c|}{ Histórico familiar para câncer } \\
\hline Sim & 13 & 100,0 & 0 & 0,0 & 1,06 \\
\hline Não & 178 & 94,7 & 10 & 5,3 & \\
\hline
\end{tabular}

Excluídas as não envolvidas diretamente na assistência ao paciente, que nunca realizaram o exame de Papanicolaou ou não estar na idade de realizar.

Fonte: (TAVARES; RÊGO, 2011) 


\section{Discussão}

O fato de o médico ginecologista compartilhar os resultados dos exames e informações sobre câncer da mama apresentou relação com aumento do conhecimento sobre câncer da mama entre as trabalhadoras. Este achado está de acordo com vários estudos sobre o assunto. Em um estudo nos EUA, comparando-se duas amostras de mulheres da população geral, entre aquelas que discutiam os parâmetros para o rastreamento do câncer da mama com seus médicos, houve maior taxa de adesão à realização da mamografia. (ROETZHEIM; FOX; LEAKE, 1994) Entre mulheres com mais de 65 anos, o aumento da habilidade na comunicação médico/paciente foi muito efetiva na estratégia de aprendizado sobre o câncer da mama, o que aumentou as taxas de rastreamento da doença no geral. (FOX; SIU; STEIN, 1994) Numa população semelhante, também houve associação entre a recomendação médica e a realização da mamografia entre essas mulheres. (SCHONBERG et al., 2007)

Em um estudo de intervenção educacional sobre câncer da mama entre mulheres imigrantes nos EUA, após o período de cinco meses de sessões sobre a importância do rastreamento e saúde da mama, houve um nítido aumento no conhecimento sobre o câncer da mama $(\mathrm{p}<0,01)$ e com maior impacto $(\mathrm{p}<0,001)$ quando relacionado à indicação precoce da mamografia pelo médico que as acompanhava. (YI; LUONG, 2005) Extensa metaanálise realizada por Legler e colaboradores (2002) traz, entre outros resultados, que em intervenções direcionadas individualmente em serviços de saúde, demonstraram-se efeitos impressionantes na realização da mamografia, entre outros fatores, com fortes motivadores as recomendações do médico e outros profissionais de saúde para a realização do exame.

Maior conhecimento foi também relacionado à história familiar positiva para câncer da mama. Este dado foi pouco abordado pelos estudos revisados, sendo os resultados conflitantes. Em um estudo realizado entre mulheres com diagnóstico de câncer, a realização de mamografia foi $28,1 \%$ maior $(\mathrm{p}<0,001)$ entre as mulheres que tinham parentes com câncer da mama do que aquelas mulheres que não tinham histórico na família. (SOUZA et al., 1998) No estudo de Roetzheim, 
Fox e Leake (1994), o histórico familiar positivo para câncer da mama não influenciou na aderência aos métodos de rastreamento.

No presente estudo, houve fraca associação entre a experiência profissional com o câncer da mama e conhecimento sobre este câncer. Esses dados são semelhantes aos de alguns estudos internacionais. Nos EUA, foi realizado um estudo com estudantes universitárias, incluindo estudantes de enfermagem, utilizando-se um instrumento denominado de Pesquisa do Conhecimento e Percepções sobre Câncer de Mama (Breast Cancer Perceptions and Knowledge Survey - BCPKS) adaptado de um instrumento maior, o Modelo de Crença na Saúde (Health Belief Model), que contempla conhecimento, susceptibilidade, severidade, barreiras e benefícios dos métodos de detecção precoce do câncer da mama. Nesse estudo, apenas o bloco sobre o conhecimento foi utilizado. O nível de conhecimento em câncer da mama no geral foi de 7,48 (máximo de 12 pontos) com acerto de $62 \%$. As estudantes de enfermagem tiveram um menor acerto $(7,46)$ em comparação às outras estudantes (7,50). (POWE et al., 2005) Em um estudo no Irã, com a população feminina geral e utilizando o BCPKS, a média de acertos para a percepção do câncer da mama e conhecimento foi de cinco (máximo de 10 pontos) com acerto de apenas 45,6\%. (PARSA; KANDIAH, 2005)

Ainda em relação ao conhecimento, no estudo de Sean e Tan (2007), a maioria das enfermeiras declarou ter alguma experiência com câncer da mama (77\%). No entanto, sobre a progressão da idade e uso de TRH, $32 \%$ e $37 \%$ das enfermeiras não sabiam que estes eram fatores de risco para o câncer da mama, respectivamente. Nos EUA em um estudo entre médicos, médicos residentes e enfermeiras, 90\% dos profissionais se declaram aptos a indicar corretamente as pacientes que deveriam realizar a mamografia e a frequência do exame. Tomando como base as diretrizes da American Cancer Socety (ACS) e da Força Tarefa de Serviços de Prevenção (USPSTF), aproximadamente $98 \%$ dos profissionais sabiam que a mamografia é efetiva na redução da mortalidade entre mulheres entre 50 a 69 anos, mas apenas $38 \%$ sabiam que o exame não é efetivo nas maiores de 70 anos. Entre mulheres com história familiar para câncer da mama entre parentes do primeiro grau, para a maioria (56\%), a indicação do rastreamento deveria ser iniciada aos 30 anos. (JOHNSON et al., 1998) 
Em outro estudo no Brasil envolvendo médicos clínicos, não houve acerto em relação aos métodos de prevenção para o câncer da mama pelo INCA, pela ACS ou pela Canadian Task Force(CTF). Os resultados mostraram que os médicos solicitavam $83,8 \%$ mais mamografias do que o adequado. Ao mesmo tempo, houve um déficit de $16,2 \%$ nas solicitações das mamografias para mulheres com indicação de realizála. (TUCUNDUVA et al., 2004) No presente estudo, não foi encontrada influência da progressão do tempo de serviço sobre o nível de conhecimento do câncer da mama. Outros estudos mostraram conflitos com os resultados apresentados. Médicos de um serviço universitário, comparados aos médicos residentes, sabiam mais que estes em relação ao aumento do risco do câncer nas classes sociais com menor poder econômico $(24 \%$ e $4 \%$ respectivamente p $<0,10)$, que o autoexame não reduz a mortalidade $(54 \%$ e $20 \%$ respectivamente, $\mathrm{p}<0,05)$ e que a mamografia em maiores de 70 anos também não reduzia (60\% e $24 \%$ respectivamente, $\mathrm{p}<0,05)$. (JOHNSON et al., 1998) Médicas norte-americanas que tinham mais de 15 anos de serviço mostraram maior conhecimento do que aquelas com menos tempo de serviço. (JAIN et al., 2006) Outro estudo cita o tempo de serviço dos trabalhadores, mas não o correlaciona ao nível de conhecimento sobre câncer da mama. (LURIE et al., 1997)

Consciência da prevenção, estar na idade para realizar o exame, por ser um exame de rotina, solicitação médica e vontade própria, foram os principais motivos que levaram a realização da mamografia regularmente. O conhecimento adequado sobre o câncer da mama, acesso aos serviços de saúde através de convênios particulares e tempo de serviço maior do que 10 anos influenciaram positivamente para a realização da mamografia. Estes dados foram condizentes com outros estudos na literatura. Entre mulheres provenientes de países asiáticos e de ilhas do pacífico, observaram-se associações entre a realização da mamografia e ter sido avaliada por um médico no último ano $(\mathrm{OR}=5,6$; IC 95\%: $3,7-8,4)$ e possuir um convênio de saúde (OR=2,1; IC 95\%: 1,2-3,7). Neste mesmo estudo, os fatores que levaram à realização do exame clínico da mama foram: não estar apta para o trabalho $(\mathrm{OR}=4,8$; IC 95\%: $1,4-15,9)$, ter sido avaliada por um médico no último ano $(\mathrm{OR}=4,3$; IC 95\%: 2,8-6,5) e possuir um convênio de saúde (OR=2,8; IC 95\%: 1,5-5,0). (COUGHLIN; UHLER, 2000) 
Em um estudo entre mulheres com tumor da mama na zona rural dos EUA, foi estudada a atitude em realizar mamografia de seguimento e observaram-se associação com: ser afrodescendente americana $(\mathrm{OR}=1,46$; IC 90\%: 1,07-2,00), discussão pelo médico sobre seu risco para desenvolver câncer da mama (OR=1,51; IC 90\%: 1,14-2,00) e realização de mamografia prévia ( $O R=0,63$; IC 90\%: 0,44-0,89). (ALTPETER; MITCHELL; PENNELL, 2005) No Brasil entre as mulheres que realizavam a mamografia regularmente os principais motivos foram a importância de tranquilizar-se e o autocuidado. (FERREIRA; OLIVEIRA, 2006)

Entre as trabalhadoras que não realizavam a mamografia regularmente, mesmo quando indicado, os principais fatores foram: descuido falta de tempo, custo do exame e medo de ser mal tratada durante a realização do exame. No estudo de Johnson e colaboradores (2008), as principais barreiras para a realização da mamografia pelos pacientes na visão dos profissionais de saúde foram: medo da dor ou desconforto (91\%); pouco entendimento sobre os benefícios da detecção precoce (89\%); percepção que a mesma não está em risco para o desenvolvimento do câncer da mama (85\%); dificuldades para transporte (79\%); custo do exame $(72 \%)$ e medo que a mamografia possa causar câncer (47\%). No estudo de Sean e Tan (2007), 21\% das enfermeiras entrevistadas acreditavam que estariam imunes ao câncer da mama se não possuíssem nenhum fator de risco. Cinco por cento das trabalhadoras acreditavam que a radiação emitida pelo mamógrafo poderia ser um fator de risco e $12 \%$ não tinham certeza.

Médicos brasileiros, quando interrogados quanto a possíveis barreiras para o adequado exercício do rastreamento do câncer, consideraram a falta de agentes educadores em saúde para a população $(82,9 \%)$ e sua própria falta de conhecimento ou treinamento $(77,1 \%)$ para fazer este tipo de rastreamento. (TUCUNDUVA et al., 2004) Em um estudo populacional no Irã, a atitude na rotina de rastreio do câncer da mama foi pobre em $10,4 \%$ das mulheres, moderada para $10,1 \%$ e boa atitude para $79,5 \%$ das entrevistadas. As principais barreiras para realização dos exames foram: pouco conhecimento de como realizá-lo (48\%), esquecimento (20\%), medo de encontrar uma massa (17\%), não achar necessário (9\%) e pouco tempo disponível (4\%). (PARSA; KANDIAH, 2005) 
O fato de a trabalhadora ser profissional da área de saúde apresentou relação com aumento do conhecimento sobre o câncer do colo do útero. Este dado está de acordo com alguns estudos sobre o tema. Em um estudo no México, com trabalhadoras da área de saúde, a classificação geral média do conhecimento foi de oito acertos, sendo considerada baixa. Como esperado, as médicas tiveram um maior número de acertos (média de 12). (GONZÁLEZ-SALINAS et al., 1996) Em outro estudo com médicos mexicanos generalistas e ginecologistas-obstetras, $79 \%$ daqueles e $86 \%$ destes sabiam que o HPV é identificado como a principal causa de câncer do colo do útero. Os generalistas, no entanto, atribuíam mais importância à hereditariedade como fator de risco e citavam menos outros fatores, como pobre higiene genital, uso de anticoncepcional oral e tabagismo. Houve uma grande discrepância quanto à idade para se iniciar a realização do exame de Papanicolaou e sua frequência; $87 \%$ dos generalistas e $32 \%$ dos especialistas responderam que a prevenção deveria se iniciar após o primeiro intercurso sexual e $73 \%$ de ambos os grupos indicariam exame anual mesmo se normal anteriormente. (ALDRICH et al., 2005)

Em mais um estudo com médicos de família norte-americanos, a maioria (89\%) concordou que a infecção por HPV era o principal fator de risco para desenvolvimento do câncer do colo do útero. A maior proporção de acertos ocorreu entre as médicas que atuavam fora do setor privado e que participavam de grupos de trabalho multidisciplinar. (JAIN et al., 2006) Em um estudo entre estudantes de enfermagem, foi reconhecido que é necessário realizar a prevenção do câncer do colo do útero, assim como a sua periodicidade e a forma correta de fazer tal prevenção. Isto levava as estudantes anualmente a procurar um profissional especializado para realizar o exame de Papanicolaou. (BEGHINI et al., 2006)

Outros estudos demonstraram resultados diferentes sobre o tema. No estudo de Mutyaba, Mmiro e Weiderpass (2006), entre trabalhadores alocados num hospital de referência em câncer, o conhecimento sobre o câncer do colo do útero foi baixo. A maioria dos participantes (81\%) sabia que o câncer do colo do útero é curável se detectado nos estágios iniciais e que o exame de Papanicolaou (83\%) poderia detectar tais lesões; no entanto, o conhecimento sobre os fatores de risco (29\%) e rotina de periodicidade do Papanicolaou (39\%) foi baixo. No 
estudo realizado por Tucunduva e colaboradores (2004), com médicos generalistas, apenas $37,14 \%$ seguiam corretamente as diretrizes fornecidas pelo INCA para a prevenção deste câncer. Dentro deste contexto, $29,3 \%$ recomendavam de maneira excessiva o Papanicolaou e $24,1 \%$ de maneira insuficiente. Em um estudo com enfermeiras sul africanas que prestavam assistência na atenção básica, apenas $58 \%$ eram suficientemente treinadas para realização do preventivo; na zona rural esses números caiam para $14 \%$. Apenas $35 \%$ dessas enfermeiras realizavam o Papanicolaou na população assistida. (KAWONGA; FONN, 2008)

Maior conhecimento sobre o câncer do colo do útero foi também relacionado com história familiar de câncer, mas poucos estudos trazem essa discussão. Isto se deve, provavelmente, ao fato de não haver associação descrita entre o risco de desenvolver o câncer do colo do útero e hereditariedade. Em um estudo colombiano, a história familiar de câncer não foi associada à realização do exame de Papanicolaou $(\mathrm{RP}=0,9$; IC 95\%: 0,7-1,2). (CASTRO-JIMÉNEZ; VERA-CALA; POSSO-VALENCIA, 2006) Em um estudo com mulheres espanholas, o comportamento sexual e hereditariedade foram apontados pelas entrevistadas como duas das principais causas do câncer do colo do útero. No geral o conhecimento sobre o câncer e a relação com a infecção por HPV era muito limitada ou inexistente. (VANSLYKE et al., 2008) No estudo de caso com mulheres da população geral, a herança genética levou algumas entrevistadas a pensar sobre a realização do Papanicolaou. (DUAVY et al., 2007)

Não houve mudança do nível do conhecimento sobre o câncer do colo do útero mesmo com a progressão do tempo de serviço. Esse resultado é contraditório com alguns estudos sobre tema. No Brasil, foi observado que médicos com mais de dez anos de formado indicavam menos a realização do exame de Papanicolaou, de acordo com o INCA $(p=0,016)$. (TUCUNDUVA et al., 2004) Em outro estudo, as médicas que tinham mais de 15 anos de serviço mostraram maior conhecimento do que aquelas com menos tempo de serviço. (JAIN et al., 2006) Verificou-se que mulheres com menos de 20 anos de serviço demonstraram um maior nível de conhecimento. (GONZÁLEZ-SALINAS et al., 1996) Outros estudos citam o tempo de serviço dos trabalhadores, mas não o correlacionam ao nível de conhecimento. (LURIE et al., 1997; ALDRICH et al., 2005 e ALDRICH et al., 2006) 
A experiência profissional com câncer do colo do útero também não influenciou no nível de conhecimento das trabalhadoras. Este dado está de acordo com vários estudos. Em um estudo africano em um hospital em Uganda, $87 \%$ dos estudantes de medicina do último ano nunca tinham feito o exame especular em suas pacientes, $56 \%$ nunca haviam feito um exame especular em nenhum momento de sua formação e apenas $14 \%$ sentiam-se seguros em realizar este exame. Apesar da maioria dos participantes lidar com pacientes do sexo feminino, o exame especular era realizado por apenas $12 \%$ desses profissionais. A maioria deles também $(78 \%)$ nunca perguntou aos seus pacientes se já haviam sido rastreadas para o câncer do colo do útero. (MUTYABA; MMIRO; WEIDERPASS, 2006)

Ainda sobre esse tópico, em um estudo comparando a realização de exames de prevenção para o câncer do colo do útero na Inglaterra, foi constatando que médicas tinham uma maior experiência com a doença. Envio de lembretes e de questionamento de ter realizado o exame de Papanicolaou às pacientes foram, respectivamente, 9\% e 11\% maior entre as médicas em comparação aos médicos. Em relação às suas habilidades em realizar o preventivo, $62 \%$ das médicas disseram ser excelentes, $99 \%$ se sentiam confortáveis em realizá-lo e $89 \%$ consideravam-se responsáveis pela realização do exame nas pacientes. (LURIE et al., 1997) Em um estudo entre médicos de família nos EUA, que avaliou o conhecimento sobre o HPV e outras afecções correlacionadas, a maioria (90\%) falou que haviam prestado assistência a pacientes com alguma queixa anogenital. Entretanto, a maioria desses médicos viu poucos pacientes (dois em média) com essas afecções no último ano. Eles também viram poucos casos de infecção por clamídia ou herpes vírus (cinco em média) no último ano. (JAIN et al., 2006)

Em um estudo entre médicos mexicanos, comparando a experiência entre ginecologistas-obstetras e médico generalistas, foi observado que $30 \%$ dos obstetras e $8 \%$ dos generalistas regularmente tratavam displasia ou câncer do dolo do útero $(\mathrm{p}=0,000)$. Houve uma proporção similar (65\% e 59\%, respectivamente) entre ginecologistas/bstetras e generalistas na realização do Papanicolaou nos últimos dois meses. (ALDRICH et al., 2006) No estudo de Gonzáles-Salinas et al. (1996), as trabalhadoras que manifestaram ter experiência com câncer do colo do útero mostraram maior nível de conhecimento. Em outro estudo, 
médicos com mais de dez anos de formados, tenderam a tomar conduta insuficiente na realização do exame de Papanicolaou de acordo com o INCA $(p=0,016)$. (TUCUNDUVA et al., 2004)

Os principais motivos que levaram à realização do exame de Papanicolaou regularmente foram: o fato de ser um exame de rotina; de se ter consciência na prevenção; a vontade própria; por estar na idade de realizar e solicitação médica. O fato de o médico compartilhar informações sobre a doença, influenciou positivamente na realização de consulta de prevenção regularmente e realização do exame de Papanicolaou. Esses achados são concordantes com alguns estudos sobre o tema. No estudo de Coughlin e Uhler (2000), avaliando mulheres migrantes de ilhas do Pacífico nos EUA, entre outros fatores, ter tido consulta médica esteve associado à realização do exame de Papanicolaou nos últimos três anos. Em um estudo entre mulheres de origem vietnamita que viviam nos EUA, as variáveis que influenciaram positivamente $(\mathrm{p}<0,05)$ na realização do preventivo foram: ser casada; possuir recursos e provedor regular de cuidados de saúde; acreditar que a realização regular do Papanicolaou reduz o risco para desenvolver o câncer do colo do útero e acreditar que este é curável se detectado precocemente. (TAYLOR et al., 2004) Para mulheres colombianas os fatores que mais motivam na realização do exame são: autocuidado; preocupação pela família; e percepção de uma boa qualidade do serviço de saúde. (WISNER-CEBALLOS et al., 2006)

No Brasil, Yassoyama, Salomão e Vicentini (2005), observaram que mulheres que tiveram acesso às orientações sobre planejamento familiar e realização do exame de Papanicolaou, foram beneficiadas por ações e atividade da saúde da mulher desenvolvida na Unidade de Saúde da família. Em outro estudo com população semelhante, foi observado que o uso de tecnologias leves de comunicação aumentava o conhecimento das usuárias, por consequência, maior adesão à realização do exame de Papanicolaou. (OLIVEIRA; PINTO; COIMBRA, 2007) Outro estudo sugere que mulheres resistentes à realização de exame de Papanicolaou deveriam ser encaminhadas para médicas, pois isto poderia reduzir este efeito. No mesmo estudo, foi observado que o grande foco na prevenção levou às maiores taxas no rastreio do câncer do colo do útero para aquelas pacientes atendidas por médicas. (LURIE et al., 1997) 
Maior escolaridade também foi associada à realização adequada do exame de Papanicolaou. Estudando uma tribo indígena nos EUA, após intervenção educacional que incluiu conhecimentos sobre o câncer do colo do útero, foi encontrada associação entre a intenção $(\mathrm{OR}=4,56)$ e realização $(\mathrm{OR}=1,63)$ do exame de Papanicolaou no estrato populacional com maior nível educacional. (DIGNAN et al., 1998) Em outro estudo nos EUA, avaliando o nível de conhecimento sobre esta doença da população no geral, mulheres com mais de 12 anos de estudo iniciaram a prevenção na idade correta $12,8 \%$ mais do que aquelas com menos de 12 anos de estudo. Em relação à idade correta para suspensão do exame preventivo, a diferença foi de $27,5 \%$. A chance de sobrevivência se houvesse detecção precoce do câncer do colo do útero calculada para o grupo de maior escolaridade, seria $24,8 \%$ maior. (GAZIANO; HOROWITZ, 2001) Em um estudo populacional com mais de 100 mil mulheres indianas, entre outros fatores, níveis educacionais mais elevados estiveram associados ( $\mathrm{OR}=1,62$; IC 95\%: 1,50-1,80) com maior realização do exame de Papanicolaou. (NENE et al., 2007)

Descuidar-se, falta de tempo, considerar o exame desnecessário por não ter problemas ginecológicos, considerar o exame caro e medo de descobrir doença, foram os principais fatores para não realizar a prevenção adequadamente. Estes dados são corroborados por vários estudos. No estudo de Kawonga e Foon (2008), apesar da difusão da técnica do exame de Papanicolaou para todas as enfermeiras do setor público, em duas províncias sul-africanas, a meta de rastreamento foi cumprida apenas em $25 \%$ e $45 \%$, respectivamente. Outros fatores importantes observados para esse pobre resultado foram: falta do acesso ao tratamento após o diagnóstico de lesões precursoras do câncer; sobrecarga de trabalho das enfermeiras com o crescimento da população e consequente demanda, influindo na não realização do preventivo ou periodicidade incorreta; má distribuição dos profissionais pelo país e pouca habilidade na realização do exame por parte dessas profissionais.

Em outro estudo sul-africano entre profissionais da área da saúde, $93 \%$ dos entrevistados sabiam que o câncer do colo do útero era um problema de saúde pública, $68 \%$ achavam fácil de diagnosticar, e $65 \%$ das entrevistadas não se achavam susceptíveis, enquanto $66 \%$ dos entrevistados achavam que suas parceiras poderiam ser afetadas. Muitas enfermeiras e auxiliares achavam que o exame de Papanicolaou 
era um procedimento exclusivamente médico. Entre as entrevistadas as principais razões para não realização do exame foram: não se sentir com risco para a doença; não ter sintomas; descuido; medo da realização do exame; pouco interesse; achar que o exame é desnecessário ou estar fora da faixa de idade de risco. Além disso, 25\% delas só aceitam ser examinadas por mulheres. Entre os estudantes de medicina, 35\% não achavam que podem realizar o exame, $26 \%$ não sabiam como realizar o exame, $22 \%$ achavam que deveria ser feito por médicos mais experientes e $15 \%$ nunca pensou a respeito. (MUTYABA; MMIRO; WEIDERPASS, 2006) No estudo de Tucunduva e colaboradores (2004) médicos brasileiros, quando questionados quanto a possíveis barreiras para o adequado exercício do rastreamento do câncer do colo do útero, consideraram que a falta de agentes educadores em saúde para a população $(82,9 \%)$ e sua própria falta de conhecimento ou treinamento para fazer esse tipo de rastreamento $(77,1 \%)$, são de grande importância.

Em estudos populacionais com mulheres de alto risco para desenvolverem o câncer do colo do útero nos EUA, o custo do exame (47\%) foi a principal barreira para realização do exame. (BURGER et al., 1995) Em outro estudo, as justificativas para a não a realização do preventivo foram: falta de motivação e vergonha ( $87 \%$ das mulheres diagnosticadas com NIC e $81 \%$ com câncer invasivo); falta de exame físico por parte do médico (60\% para todas as mulheres); tempo de espera longo para a consulta ( $48 \%$ das mulheres com NIC e $60 \%$ daquelas com câncer invasor); e agendamento tardio ( $47 \%$ das mulheres com NIC e $50 \%$ daquelas com câncer invasor). (BRENNA et al., 2001)

Em outro estudo, observou-se que inatividade sexual e medo de dor ou desconforto na realização do exame estavam associados à não realização do preventivo. (TAYLOR et al., 2004) No estudo conduzido por Wiesner-Ceballos et al. (2006), as principais barreiras para realização do Papanicolaou expressadas pelas mulheres foram: vergonha; medo de dor durante a realização do exame; desaconselhamento ou impedimento por parte do companheiro; desaconselhamento ou impedimento por parte das famílias principalmente entre aquelas mais jovens; e dificuldade de acesso aos serviços de saúde (tempo de espera para marcar o exame, custo para realização do exame, atraso na entrega do resultado, má relação com a equipe de saúde e relação médico-paciente prejudicada). Em recente artigo, Rogers e Cantu, (2009) afirmam que 
a falta de conhecimento sobre a infecção pelo HPV e o quanto o exame de Papanicolaou pode detectar anormalidades no colo do útero estão associados ao aumento do risco para desenvolvimento da doença.

No Brasil, num estudo em São Luis, Maranhão, as principais barreiras que estiveram associadas com a não realização do exame de Papanicolaou foram: não ter companheiro; menor escolaridade; viver em domicílio cujo chefe de família é trabalhador braçal e não ter realizado consulta médica nos últimos meses. (OLIVEIRA et al., 2006) Em outro estudo com mulheres atendidas em unidades básicas de Fortaleza, Ceará, as principais barreiras na realização do preventivo foram: vergonha em realizar o exame; desconforto da posição para realização do preventivo; medo de dor na realização do exame; medo do diagnóstico do câncer do colo do útero; realização do exame por profissional do sexo masculino; impedimento por parte do companheiro e dificuldades no acesso aos serviços de saúde (desinformação sobre a maneira da realização do exame, despesas para realização do exame, tempo de espera para agendar ou realizar o exame e falta de material para realizar o exame). (DUAVY et al., 2007) Na Bahia, analisando o discurso de mulheres atendidas no SUS, a falta de esclarecimento e conhecimento das mulheres sobre o seu corpo; implicava no não entendimento sobre o exame de Papanicolaou como relacionado à prevenção do câncer do colo do útero. Além disso, a dificuldade de acesso à assistência médica foi outro ponto importante na não realização do exame. (BARROS, 2005)

\section{Considerações finais}

Este estudo agrega algumas informações ao conhecimento corrente sobre atitudes de prevenção dos cânceres da mama e do colo do útero. Traz dados sobre o conhecimento prático das trabalhadoras de saúde sobre o assunto em relação às atuais diretrizes do INCA. Chama a atenção também como o meio pode interagir com fatores sociais e pessoais, podendo ser cruciais no entendimento de uma atitude preventiva.

Os principais motivos que levaram essas profissionais a realizar a mamografia regularmente foram à consciência da prevenção, estar na idade de realizar, por ser parte dos exames de rotina, solicitação médica e vontade própria. Nesta perspectiva, o conhecimento adequado sobre o câncer da mama, o acesso aos serviços de saúde através de 
convênio particular ou da empresa e tempo de serviço maior que 10 anos, contribuíram positivamente para a realização do exame. Para a minoria, que não realizava a prevenção como recomendada, as principais barreiras foram: descuido de sua saúde; falta de tempo; custo do exame e medo de ser mal tratada durante a realização do exame. Quanto ao câncer de colo do útero, os principais motivos que levaram essas profissionais a realizar o exame preventivo foram: ser parte dos exames de rotina; consciência da prevenção; vontade própria; estar na idade de realizar e solicitação médica. Nesta perspectiva, o compartilhamento de informações sobre o câncer do colo do útero pelo médico e maior escolaridade, contribuíram positivamente para a realização do exame. Para a minoria que não realizava a prevenção como recomendada, as principais barreiras foram: descuido falta de tempo; considerar o exame desnecessário por não ter problemas ginecológicos; custo do exame e medo de descobrir doença.

Em conclusão, encontrou-se uma atitude positiva das trabalhadoras da área de saúde quanto à prevenção dos cânceres da mama e do colo do útero. Recomenda-se, entretanto, cautela quanto à generalização desses resultados mesmo para outras trabalhadoras da saúde, em função de algumas importantes limitações do estudo. Citam-se, principalmente, o tamanho da população estudada e as perdas. Outros estudos com maior número de profissionais são necessários para corroborar os resultados aqui evidenciados. É importante, o incentivo das instituições formadoras e os locais de trabalho dessas profissionais, tanto no setor privado como no público, para a educação continuada. Isso também é importante para elas e para que haja o repasse de informações corretas sobre a detecção precoce dessas doenças para a população no geral.

\section{Referências}

AGARWAL, G. et al. Spectrum of breast cancer in Asian women. World Journal of Surgery, v. 31, n. 5, p. 1031-1040, 2007.

ALDRICH, T. et al. Mexican physicians' knowledge and attitudes about the human papillomavirus and cervical cancer: a national survey. Sexually Transmitted Infections, v. 81, p. 135-141, 2005. 
ALDRICH, T. Cervical cancer and HPV link: Identifying areas for education in Mexico City's public hospital. Salud Pública de México, v. 48, n. 3, p. 236-43, 2006.

ALTPETER, M.; MITCHELL, J.; PENNELL, J. Advancing Social Workers' Responsiveness to Health Disparities: The Case of Breast Cancer Screening. Health \& Social Work, v. 30, n. 3, p. 221-232, 2005.

BARROS, D. O. S. Mulheres com câncer invasivo do colo do útero: estratégias de enfrentamento. 2005, 148f. Dissertação (Mestrado em enfermagem). Programa de Pós-Graduação da Escola de Enfermagem, Universidade Federal da Bahia, 2005.

BEGHINI, A. B. et. al. Adesão das acadêmicas de enfermagem à prevenção do câncer ginecológico: da teoria à prática. Texto \& Contexto Enfermagem, v. 15, n. 4, p. 637-644, 2006.

BRASIL. Instituto Nacional de Câncer / Ministério da Saúde. Tipos de câncer: Mama. Disponível em: <http://www2. inca. gov. br/wps/wcm/ connect/tiposdecancer/site/ home/ mama> Acesso em: 12 dez. 2011.

. Instituto Nacional do Câncer / Ministério da Saúde.

Tipos de câncer: Colo do Útero. 2011a. Disponível em: < http:// www2. inca. gov. br/wps/wcm/connect/ tiposdecancer/ site/home/colo_utero>. Acesso em: 12 dez. 2011.

. Instituto Nacional de Câncer/ Ministério da Saúde. Estimativa 2012: Incidência de Câncer no Brasil. 2011b. Disponível em: <http:// www. inca. gov. br/estimativa/2012/>. Acesso em: 06 mar. 2012.

BRENNA, S. M. F. et al. Conhecimento, atitude e prática do exame de Papanicolaou em mulheres com câncer do colo uterino. Cadernos de Saúde Pública, Rio de Janeiro, v. 17, n. 4, p. 909-914, 2001.

BRODY, J. G.; TICKNER, J.; RUDEL, R. A. Community-Initiated Breast Cancer and Environment Studies and Precautionary Principle. Environmental Health Perspectives, v. 113, n. 8, p. 920-925, 2005.

BURGER, R. A. et al. Single-Visit Program for Cervical Cancer Prevention in a High-Risk Population. Obstetrics \& Gynecology, v. 86, n. 4, p. 491-8, 1995.

CASTRO-JIMÉNEZ, M. A.; VERA-CALA, L. M.; POSSO-VALENCIA, H. J. Epidemiología del cáncer de cuello uterino: Estado del arte. Colombiana de Obstetricia y Ginecología, v. 57, n. 1, p. 182-189, 2006.

COSTA, J. S. D. da et al. Cobertura do exame citopatológico na cidade de Pelotas, Brasil. Panamericana Salud Publica, v. 3, n. 5, p. 308-313, 1998. 
COUGHLIN, S. S.; UHLER, R. J. Breast and Cervical Cancer Screening Practices among Asian and Pacific Islander Women in the United States, 1994-1997. Cancer Epidemiology Biomarkers Prevention, n. 9, p. 597-603, 2000.

CRUZ, L. M. B. da; LOUREIRO, R. P. A Comunicação na Abordagem Preventiva do Câncer do Colo do Útero: importância das influências histórico-culturais e da sexualidade feminina na adesão às campanhas. Saúde e Sociedade, v. 17, n. 2, p. 120-31, 2008.

DELUCA, G. D. et al. Human papilomavirus in women with cervical cytological abnormalities from an area with high incidence of cervical cancer. Instituto de Medicina Tropical, São Paulo, v. 46, n. 1, p. 9-12, 2004.

DIGNAN, M. B. et al. Health education to increase screening for cervical cancer among Lumbee Indian Women in North Caroline. Health Education Research, v. 13, n. 4, p. 545-556, 1998.

DUAVY, L. M. et al. A percepção da mulher sobre o exame preventivo do câncer cérvico-uterino: estudo de caso. Ciência \& Saúde Coletiva, v. 12, n. 3, p. 733-742, 2007.

FERREIRA, M. L. M.; OLIVEIRA, C. Conhecimento e significado para funcionárias de indústrias têxteis sobre prevenção do câncer do colo-uterino e detecção precoce do câncer da mama. Revista Brasileira de Cancerologia, v. 52, n. 1, p. 5-15, 2006.

FOX, S. A.; SIU, A. L.; STEIN, J. A. The importance of physician communication on breast cancer screening of older women. Archives of Internal Medicine, v. 154, n. 18, p. 2058-2068. 1994.

GAZIANO, C.; HOROWITZ, A. Knowledge Gap on Cervical, Colorectal Cancer Exist Among U. S. Women. Newspaper Research Journal, v. 22, n. 1, p. 12-27, 2001.

GODINHO, E. R.; KOCH, H. A. Rastreamento do câncer de mama: aspectos relacionados ao médico. Radiologia Brasileira, v. 37, n. 2, p. 91-99, 2004.

GONZÁLEZ-SALINAS, C. et al. Conocimientos y actitudes de trabajadoras de salud em torno al programa de detección oportuna de cáncer cérvico-uterino. Atención Primaria, v. 18, n. 5, p. 237-42, 1996.

JAIN, N. et al. Family Physicians' Knowledge of Genital Human Papillomavirus (HPV) Infection and HPV-related Conditions, United States, 2004. Family Medicine, v. 38, n. 7, p. 483-489, 2006.

JOHNSON, K. M. et al. Inner city primary care provider's breast cancer screening knowledge: implications for intervention. Journal of Community Health, v. 23, n. 1, p. 1-13, 1998. 
KAWONGA, M.; FONN, S. Achieving effective cervical screening coverage in South Africa through human resources and health systems development. Reproductive Health Matters Journal, v. 16, n. 32, p. 32-40, 2008.

KERLIKOWSKE, K. Evidence-Based Breast Cancer Prevention: The Importance of Individual Risk. Annals of Internal Medicine, v. 151, n. 10, p. 750-752, 2009.

LEGLER, J. et al. The Effectiveness of Interventions to Promote Mammography among Women with Historically Lower Rates of Screening. Cancer Epidemiology, Biomarkers \& Prevention, n. 11, p. 59-71, 2002.

LUQUIS, R. R.; CRUZ, I. J. Knowledge, attitudes, and perceptions about breast cancer and breast cancer screening among Hispanic women residing in south central Pennsylvania. Journal of Community Health, v. 31, n. 1, p. 25-42, 2006.

LURIE, N. et al. Why Do Patients of Female Physicians Have Higher Rates of Breast and Cervical Cancer Screening? Journal of General Internal Medicine, n. 12, p. 34-43, 1997.

MURTA, E. F. C. et al. Câncer do Colo uterino: correlação com o início da atividade Sexual e Paridade. Revista Brasileira de Ginecologia e Obstetrícia, v. 21, n. 9, p. 555-559, 1999.

MUTYABA, T.; MMIRO, F. A.; WEIDERPASS, E. Knowledge, attitudes and practices on cervical screening among the medical workers of Mulango Hospital, Uganda. BMC Medical Education, v. 6, n. 13, 2006. Disponível em: <http://www. biomedcentral. com/1472-6920/6/13 >. Acesso em: 25 ago. 2009.

NENE, B. et al. Determinants of women's participation in cervical screening trial, Maharashtra, India. Bulletin of the World Health Organization, n. 85, p. 264-272, 2007.

OLIVEIRA, M. M. H. N. et al. Cobertura e fatores associados a não realização do exame preventivo de Papanicolaou em São Luís, Maranhão.

Revista Brasileira de Epidemiologia, v. 9, n. 3, p. 325-34, 2006.

; PINTO, I. C.; COIMBRA, V. C. C. Potentialities in integral care: uterine cervical cancer prevention according to the users of the family health strategy. Revista LatinoAmericana de Enfermagem, v. 15, n. 3, p. 426-30, 2007.

PARSA, P.; KANDIAH, M. Breast cancer knowledge, perception and breast self-examination practices among Iranian women. The International Medical Journal, v. 4, n. 2, p. 17-24, 2005. 
PINHO, A. A.; MATTOS, M. C. F. I. Validade da citologia cervicovaginal na detecção de lesões pré-neoplásicas e neoplásicas de colo de útero. Jornal Brasileiro de Patologia e Medicina Laboratorial, v. 38, n. 3, p. 225-231, 2002.

POWE, B. D. et al. Perceptions About Breast Cancer Among College Students: Implications for Nursing Education. Journal of Nursing Education, v. 44, n. 6, p. 257-265, 2005.

RODRÍGUEZ, M. A.; WARD, L. M.; PÉREZ-STABLE, E. J. Breast and Cervical Cancer Screening: Impact of Health Insurance Status, Ethnicity, and Nativity of Latinas. Annals of Family Medicine, v. 3, n. 3, p. 235-241, 2005.

ROETZHEIM, R. G.; FOX, S. A.; LEAKE, B. The effect of risk on changes in breast cancer screening rates in Los Angeles, 1988-1990. Cancer, v. 74, n. 2, p. 625-631, 1994.

ROGERS, N. M.; CANTU, A. G. The Nurse's in the Prevention of Cervical Cancer Among Underserved and Minority Populations. Journal of Community Health, v. 34, p. 135-143, 2009.

SCHONBERG, M. A. et al. Factors influencing elderly women's mammography screening decisions: implications for counseling. BMC Geriatrics, n. 7, p. 26, 2007. Disponível em <http://www. biomedcentral. com/1471-2318/7/26> . Acesso em: 22 fev. 2012.

SEAH, M.; TAN, S. M. Am I breast cancer smart? Assessing breast cancer knowledge among healthcare professionals. Singapore Medical Journal, v. 48, n. 2, p. 158-62, 2007.

SOUZA, R. M. et al. História Familiar em Segundo Grau como Fator de Risco para Câncer de Mama. Revista Brasileira de Ginecologia e Obstetrícia, v. 20, n. 8, p. 469-473, 1998.

SPSS Inc, Chicago, IL, 2004. Disponível em:<http://www. manta. com/c/mm7z120/spss-inc> Acesso em: 25 fev. 2012.

TAYLOR, V. M. et al. PapTestingAdherenceAmongVietnamese American Women. Cancer Epidemiology, Biomarkers \& Prevention, v. 13, n. 4, p. 613-619, 2004.

THOMPSON, B.; MONTAÑO, D. E.; MAHLOCH, J. Attitudes and Beliefs Toward Mammography Among Women Using an Urban Public Hospital. Journal of Health Care for the Poor and Underserved, v. 8, n. 2, p. 186-201, 1997.

TUCUNDUVA, L. T. C. et al. Estudo da atitude e do conhecimento dos médicos não oncologistas em relação às medidas de 
prevenção e rastreamento do câncer. Revista da Associação

Médica Brasileira, v. 50, n. 3, p. 257-262, 2004.

VALDEZ, A. et al. A multimedia breast cancer education intervention for lowincome Latinas. Journal of Community Health, v. 27, n. 1, p. 33-51, 2002.

VANSLYKE, J. G. et al. HPV and Cervical Cancer Testing and

Prevention: Knowledge, Beliefs, and Attitudes Among Hispanic Women.

Qualitative Health Research, v. 18, n. 5 p. 584-596, 2008.

WISNER-CEBALLOS, C. et al. La Citología de Cuello Uterino em Soacha, Colombia: Representaciones Sociales, Barreras y

Motivaciones. Revista Salud Pública, v. 8, n. 3, p. 185-96, 2006.

YASSOYAMA, M. C. B. M.; SALOMÃO, M. L. M.; VICENTINI, M. E.

Características das mulheres que realizam exame preventivo do colo de útero durante a gestação: bases para estratégias do Programa de Saúde da Família (PSF). Revista Arquivo Ciências da Saúde, v. 12, n. 4, p. 172-176, 2005.

YI, J. K.; LUONG, K. N. T. Apartment-based Breast Cancer Education Program for Low Income Vietnamese American Women. Journal of Community Health, v. 30, n. 5, p. 345-353, 2005. 